\title{
Re - A hidden agenda for educational technology in Australia
}

\begin{abstract}
Sue McNamara
Monash University

EdTech'88, the biennial conference of the Australian Society for Educational Technology witnessed numerous demonstrations of the applications of technology to instruction. Predominantly attention focused on the mechanisms of the technology and their attributes applied to a wide range of instructional problems. Underlying the practical implementation of the technology however were concerns which might best be described as a 'hidden agenda'. Garth Boomer alluded to a series of non-technology based considerations from which items for this agenda might be derived. This article discusses those items and suggests that they may provide a parallel working model (to design considerations) for the future development of educational technology in Australia.
\end{abstract}

Convincing government, education and the general public of the worth of educational technology is no small undertaking. Not only have the conventions of economy and efficiency to be addressed, but the traditions of doubt and skepticism often associated with technology have also to be overcome. Fundamental to the process is that complex quality known as human nature.

The advantages and potential of technology in instruction are well known to those conversant with the field, but not everyone belongs to this group. If one mentions the term 'educational technology' to a group of nontechnologically minded individuals the immediate reaction is quite likely to be one implying that the speaker is addressing the listeners in a foreign language. And that might well be the case. The tendency of those familiar with the area to use terminology and language intrinsic to the field is a problem. Of course, it is not merely a problem for educational technology. It occurs throughout the various disciplines, but because educational technology is involved in a broad spectrum of fields, and at many different levels the problem is perhaps of a greater magnitude here than elsewhere. 
Claims for the potential of the technology (and thus support for the development of the field) must be justified across a wide variety of policy and decision-making bodies whose knowledge and understanding of the field is highly variable.

To date, the development of the field of educational technology has seen emphasis placed on the technology or the use of it, with development models focusing on precise objective, task-based factors, and the application of technology to solving task-related problems. Considerations of communication with the wider community have been relegated to the fringe. In response to the challenges being put before educational technology by government and society it is perhaps timely to consider the development of a parallel model, (in conjunction with design models) which addresses the social or cultural conventions (e.g. Mangan, 1978), acceptance and integration of technology into the wider community.

\section{What is meant by the Culture of Educational Technology?}

"Here's how. You create your file in the word processing package you are using. You then save it, go to the file convert section of the menu, turn it into an ASCII file and then you can import it into the statistics program as a text file."

Such are the instructions in many a computer manual. No, they are not intended for the novice or inexperienced user, but even those familiar with much of the language of the technology sometimes have difficulty interpreting the codes. However language is but one aspect of the culture of the technology.

Let's take a more common analogy from which a definition of culture might be obtained; settling into a new country. Some of the experiences to be had include - learning the language (both written and spoken and the colloquialisms inherent in that language), the social customs, community variation, geography, climate, legal system, rules and regulations and the politics of the country. All of these components can loosely be referred to as cultural aspects of the country. The culture of technology is not unlike this.

\section{Language}

Technologies contain their own language, much of which could not be called universal. A more appropriate comparison would be to the dialects of different languages. The terminology of the computer has introduced another dimension into the English language (and presumably other tongues too), the uniting of the computer with other technologies such as video further complicating matters. Bytes, drives, disks and formats are 
common terms in the technology vocabulary. Although it is inevitable that new terms are generated to describe discrete or unique components or operations associated with the technologies, these terms can also alienate many an individual whose comprehension of them (and the context in which they are intended) is prohibiting. Likewise the 'borrowing' of a symbolic term or phrase (e.g. menu, cut and paste,) introduces a semiotic level of understanding which occasionally requires the individual to cope with a new and alternate meaning. Hade (1982), Cassidy (1982) and Nugent (1982) discuss the role of semiotics and literacy in relation to technology in education. One could pursue this line of thought in some depth, but the purpose here is to make the point that in order to fully understand the technology and its role one should have at least adequate knowledge and understanding of the language of the technology. It is thus an important part of the culture of the technology.

\section{Community Variation, Social Customs}

As anyone endeavouring to launch into the purchase of a computer, video recorder, or still camera will know variation is the 'name of the game'. According to the wisdom of the manufacturers and the logic of the salesman, Model A is never as good as Model B, nor will it have the capabilities, facilities etc. etc. And each program has its own idiosyncrasies. Videodisc materials produced in the United States via NTSC cannot be played on the now Australian Standard (PAL) players and of course as yet, there exists no standard driver package for the growing number of interactive discs being produced here. The interaction component of each package requires a largely dedicated system (although other programs can be located on the computer too). Such might be called the community variations of the culture.

Away from the hardware, the roles of educational technology in the various institutions and organizations across the country differ greatly. At one extreme is the 'one man (or woman) band' operation in which the educational technologist is expected to be designer, maintenance technician, operator and so forth while at the other extreme the larger units comprise numerous personnel in specialist roles of curriculum designer, consultant, scriptwriter, computer programmer or instructional designer. The specific skills of computer programming, authoring or technical production are also being designated 'educational technologist' in many cases in business, industry and education. The competency study of the American Society for Training and Development (1983) and the similar but later Canadian report (Suessmuth \& West 1987) list numerous competencies which might be classified as roles of educational technologists. The diversity of specification of 'educational technologist' 
and educational technology could be likened to differences in social customs of a community and is very much a part of the culture of the technology.

\section{Geography, Climate}

(Although not strictly 'cultural' this item is considered important in its relationship to the language, social and legal aspects of the culture). Very simply the geography of technology could be the conditions under which the technology is employed in instruction or education, the climate being the components of the hardware and software. Thus the classroom, laboratory, distance education mode, or instructional environment are representative of the geographical considerations, the choice of 'standalones' or networking, peripherals, the use of mainframe or pc, the configuration of systems, the differences between one inch and VHS formats of video, or print materials produced via desktop publishing or photographic production techniques being considered as climatic factors.

\section{The Legal System, Rules, Regulations - and Politics}

With plenty of room for differences of opinion, the various models and structures of design (e.g. Dick and Carey, 1978; Kemp, 1985; Fuller, 1987) might be thought of under this heading. Good design necessitates the following of prescribed rules and regulations in order to address the problems and reach optimal solutions. On a different organizational level the relationship between government, decision making bodies and those working "in the field" of educational technology should also be considered in this category. More of an administrative focus than the preceding aspects of language, social components and geographical factors, this item encompasses them all and could make - or break - the future of educational technology in Australia. A public awareness is needed of the elements within the area of legalities and rules and regulations which govern the discipline, as is an awareness of the highly political nature of its development. The role played by the often fickle and contradictory, or fragile and transient nature of political support can result in precarious and somewhat inappropriate development decisions being made. Thus the legalities, rules, regulations and political aspects of technology are another crucial component of the culture of technology.

\section{An agenda in context}

It is relatively easy to lay blame or point a finger at government, society or education in general for the present dilemmas facing educational technology in this country and say that "they just don't understand". It is a little more difficult to overcome this problem of lack of understanding. But 
it is here that an agenda which addresses the cultural aspects of technology in instruction and education may assist the process. Further the development of a model based on this agenda may serve to initiate a more comprehensive approach to the discipline. This model would comprise present and future design considerations and corresponding cultural considerations. The present crisis in education in Australia today lends itself as an illustration of the possibilities of a hidden agenda based on cultural considerations and the eventual model.

\section{"Re" - The Starting Point}

"Re" seems to be the most popular prefix in government, education and training circles today. The terms review, restructure, retrain and even retrench have brought frowns to the faces of many an educationalist. Educational technology is no exception. Other terms such as rationalization, amalgamation and accountability have also generated predominantly negative reactions in the educational community.

Despite the illustrations of the potential of the technology at the recent conference there existed (and exists throughout education in Australia at present) an atmosphere of apprehension. This apprehension might be described as a "fear of the unknown". This fear may be the result of a number of factors but collectively can be attributed to the upheavals currently occurring in education across Australia. Further, while the voice of the conference was dominated by the tertiary sector, the guise of massive and radical change has also enveloped the secondary and primary sectors of education over the past few years. Moreover industry, business and commerce have not escaped the net with substantial changes to training and technology within these sectors now being forecast.

Admittedly much of the negative reaction to the rhetoric about the future of education, and in this case educational technology, is in most cases justifiable. The emphasis being placed on rationalization and accountability has overshadowed potential developments in the area of technology for learning, and the lack of definitive moves by government or education has been the subject of much debate. With each of the 're's' has come a period of indecision and stagnation in policy making and implementation. One positive outcome of the whole 're' exercise though might be the opportunity for educational technology, as a discipline to 'regroup, reconsider and rethink'. After all it is a needs-based, problemsolving discipline. From the point of view of educational technology one might suggest that much of the present episode is due to an initial lack of understanding on the part of both educational technology and bodies outside the discipline. Rightly or wrongly the path might look like; lack of understanding leads to apprehension which in turn leads to indecision resulting in stagnation and so forth and so on until the final chapter reads 
like a battle for survival. (Such a picture could well describe the situation for some of those involved in educational technology in educational institutions today).

Without oversimplifying or underestimating a situation rather more complex than the preceding description acknowledges, it might be recommended that in view of the stagnation of policy and decision making, perhaps it is time that those involved with educational technology stopped looking to government and educational administration for directions and leadership and instead took the alternative of providing direction and leadership. In order to do this, common communication links must be established through the sharing of cultural experiences. These links might be provided in a model developed from the hidden agenda.

To some extent, given the present context of change in education, educational technology has a responsibility to initiate moves towards more general understanding of the 'culture' of the technology. Although technology such as the computer, the video recorder and the phone answering machine are now commonplace in many Australian homes, the relationship between even these technologies as consumer appliances and their role in the field of education is not always clear. The overlap between general applications and learning applications of the technology is at times a very fine line (if there exists a line at all), but the common tendency to categorize and classify according to traditional roles (e.g. the teacher as control, the technology as an aid) prevents recognition of the diverse nature of the technology. Rather it often motivates a comparative approach and attitude in preference to an integrated approach, which results in rejection of the technology and the concepts associated with it. The case of the teacher/instructor reluctant to use technology, having already, years ago decided it was 'too difficult' (before even trialling it) is an example of the lack of a satisfactory cultural link.

\section{Defining the Items of the Agenda}

Having loosely defined the culture of educational technology, and an example of the context in which the culture operates, the next step is to decide on the specific items on the agenda.

Item 1: To Whom it May Concern...

First and foremost on this agenda should come identification of those needing some form of understanding of the technology. Just as a good design model stipulates examination of learner characteristics, so too the establishment of a relationship between educational technology and the wider community requires educational technology to establish a consciousness and empathy with those who use, come in contact with or make decisions concerning the development and implementation of 
technology-based learning but whose understanding of the discipline is limited. This group might comprise teachers (both primary and secondary) in all disciplines, lecturers, instructors, tutors within formal educational institutions and in business, commerce and industry; administrators in all sectors, parents, councils and decision-making bodies, company boards, community groups etc. The list is endless and contact should be made at all levels. Hence it is up to the individual working in the single person enterprise to take on a liaison role within the organization, just as it is the responsibility of those employed in the larger units to promote the discipline in the wider communities of their organizations.

The aims of identifying those in the wider community from whom educational technology is presently remote is twofold. Firstly to demystify the use of technology in education and secondly to clarify the role of the many facets of the discipline from research, design or production to the 'hands on' operation and implementation of technology based instruction. As this item on the agenda deals with the community variation and social characteristics of the culture, a second item on the agenda should address the communication modes between the discipline and those outside the field.

\section{Item 2: Communication Pathways}

A quick browse through any of the educational technology or instructional development journals, texts or handbooks is enough to indicate the wealth of terminology being generated by, or included in the discipline. Acceptance of the 'jargon' and understanding of it is to some degree one of the most difficult problems facing educational technology. The cultural aspects of the language however is one which needs to be addressed if successful communication links between the discipline and the wider community are to be established. Numerous glossaries of technological terms are already available but for the purposes of educational technology the overriding educational criteria must be incorporated into the already existing technology definitions.

The need for simplicity in the language of educational technology must also be recognized. Simple terms, straightforward, succinct yet comprehensive explanations of the components, operations and uses of the technology are needed if the discipline is to be made accessible to, and be understood by the wider community. Naturally the nuances of the language should also be examined. Ways must be explored of communicating the unique aspects of educational technology beyond the level of vocabulary explanations.

The item of communication pathways is closely related to the third item suggested for inclusion in this agenda, as it is through the establishment of communication pathways that the profile of educational technology will be conveyed. 
Item 3: Building a Profile of Educational Technology

The previous discussion of the culture of the technology described the 'facts and figures' area of the roles of educational technologists and the components and operation of the these components as the geographical and climatic aspects of the culture. On the hidden agenda this aspect of the culture would perhaps be related to the development of a profile of educational technology. This profile might be viewed as an endeavour to assemble information about the many roles of the technology and technologists and the types of learning involved in the field of technology in education (Jonassen, 1985). Earlier descriptions of the relationships of educational technology with 'clients' (Hedberg, 1980) and more recent discussions of the roles (Murphy, 1987) have suggested possible avenues for exploration of this item. Data relating to the building of a profile of educational technology needs to be gathered from all areas of the field and compiled into a format which is readily accessible to the general community as well as to those working within the field.

More difficult (although the point is debatable) is the establishment of general communication about the technology itself. Woven into the fabric of educational technology are the threads of learning theories, systems theories and many other pedagogical considerations which, in essence, relegate the technology itself to a subservient role (or to a subculture status). In communicating the roles of the technology to those outside the field, a balance must be achieved between the educational component and the technological components of the discipline. Ways must also be sought of relating the two using general vocabulary in preference to technical or technological jargon.

\section{Item 4: Policies and Politics}

Each of the preceding items on the agenda will, to a large extent influence government and decision making bodies concerned with the recognition, establishment of directions for and funding of educational technology in Australia. In recent years we have seen several government enquiries into various aspects of technology in education (e.g. The AEC taskforce enquiry, the Brumby Enquiry). The extent to which the recommendations of these enquiries have been implemented is variable, but the fact remains that on an institutional, state and a national level, the decision makers are seeking directions from those in the field. The positiveness of these enquiries will naturally be influenced by one's political viewpoint but regardless of that viewpoint, it should be noted that educational technology must continue to remain involved in and contribute substantially to the formulation of policies (and the accompanying politics) regarding present and future developments.

The involvement of educational technology in policy making and thus in politics, both within the field and outside it is inevitable and crucial to its development. The present crisis in education has been referred to as an 
example of how decisions regarding other areas also effect educational technology. The contradiction of the call for emphasis to be placed on technology in education, while funding and restructuring are resulting in substantial limitations of the services offered by educational technology areas is indicative of the need for 'informed' decision making based on more than exercises on economic addition and subtraction. But it is not the custom of decision makers to come to educational technology for advice. On the contrary, educational technology must approach (and convince) the decision makers. It is perhaps at this level that the success of the development of the other items on the 'hidden agenda' will eventually be judged.

\section{Conclusion}

The culture of educational technology presents a different focus than that often put forward as the major concern of the discipline. Changing the thinking of those within the field may prove just as difficult a task as it might be for those outside the field. It is the suggestion of this article however that rather than being motivated by 'crises' which need urgent resolution, consideration must be given to long term planning (and thus the development of a model). Within this planning attention needs to be given to the consequences of technology cultural ignorance or understanding in the wider community of education and society in general. Concurrently with this argument is the suggestion that, rather than being 'driven by the technology' policies and planning need to begin with the 'human'.

Yes technology has a capacity for decision making (sometimes more appropriate than human decision making) and in many ways closely resembles humanity, but there remains one aspect of humanity that science and technology has not been able to imitate successfully - the quality of human nature.

\section{References}

Boomer, G. (1988). Introduction. In J. Steele and J. G. Hedberg (eds), Designing for Learning in Industry and Education, iv. Proceedings of EdTech'88. Canberra: AJET Publications.

http:/ / www.ascilite.org.au/aset-archives/confs/edtech88/boomer.html

Cassidy, M. (1982). Toward integration: education, instructional technology and semiotics. Educational and Communications Journal, 30(2), 75-89.

Dick, W. \& Carey, L. (1978). The Systematic Design of Instruction. Glenview, Ill.: Scott Foresman and Co.

Fuller, R. F. (1987). Setting up an interactive video project. In D. Laurillard (Ed.) Interactive Media: Working methods and practical applications. Chichester, Britain.: Ellis Horwood Limited. 
Hade, D. (1982). Literacy in the Information Society. Educational Technology, 22(8), 7-12.

Hedberg, J. (1980). Client Relationships and Instructional Design. Programmed Learning and Educational Technology, 17(2), 102-109.

Jonassen, D. H. (1985). Learning Strategies: A new educational technology. Programmed Learning and Educational Technology, 22(1), 26-34.

Kemp, J. (1985). The Instructional Design Process. NY: Harper Row.

Mangan, J. (1978). Cultural conventions of pictorial representation: Iconic literacy and education. Educational Communications and Technology Journal, 26(3), 245-267.

Murphy, G. (1987). The impact of new communication technologies on role and function in traditional education support services. Australian Journal of Educational Technology, 3(1), 25-32. http:/ / www.ascilite.org.au/ajet/ajet3/murphy.html

Nugent, G. (1982). Pictures, audio and print: Symbolic representation and the effect on learning. Educational Communications and Technology Journal, 30(3), 163-174.

Suessmuth, P. F. \& West, S. M. (1987). Competency analysis for trainers: A professional assessment and development guide. Canada: Ontario Society for Training and Development.

Author: Sue McNamara lectures in the Faculty of Education, Monash University, Clayton, Victoria, 3168.

Please cite as: McNamara, S. (1989). Re - A hidden agenda for educational technology in Australia. Australian Journal of Educational Technology, 5(1), 3746. http: / / www.ascilite.org.au/ajet/ajet5/mcnamara.html 